was composed of thirty-five plots of one chain square, or of onetenth of an acre each, and comprised forty drills or row's of plants. The plots were arranged to form five rows of seven plots each, and a rectangle of three and a half acres. They were so disposed within this area that every manured plot was adjacent to an unmanured plot, with the object of obtaining repeated confirmations of any differences which might be indicated in favour of the dressings. Every trial was made in duplicate in both series, and the results are graphically shown by tinted plans, on which the number of the plot, the manurial dressing used, and the number and weight of roots grown are printed.

Not only do these experiments prove ground basic cinder to be a valuable fertiliser, but they assign it a higher position than ground coprolite, and place it only slightly below "superphosphate" in value. This remarkable result is, we find, supported by statements resting on the authority of Dr. Biedermann Centralblatt (vol. xiv. part 2), in which the phosphoric acid in basic cinder is asserted to be more readily appropriated by growing plants than is the phosphoric acid contained in coprolites.

The subject is full of interest as bearing upon the positive profits of steel manufacture, and also upon the manufacture of superphosphate and upon agricultural practice. It has attracted the attention of M. Grandeau, of the Faculty of Science of the French University, who contributed a review of the pamphlet before us occupying over three columns of Le Temps newspaper. In the course of his remarks he says :- "Les résultats obtenus en Angleterre confurment pleinement, on le voit, ceux que les agronomes allemands ont publiés et que j'ai précédemment analysés. Les scories de déphosphoration sont appelées à jouer un rôle consiclérable dans la fumure du sol. Des négociants ont déjà traité avec quelques-unes des importantes usines de l'Est (Alsace-Lorraine notamment) pour l'achat de toute leur production de scories."

The experiments conducted at Downton and Ferry Hill were not only instituted to ascertain the positive value of ground basic cinder in comparison with unmanured plots. In them the ground cinder was compared with ground coprolite, with ordinary superphosphate, with a rich superphosphate, with a superphosphate made direct from the basic slag, and with a superphosphate to which green vitriol was added. The subject is likely to arouse a very considerable amount of attention.

\section{AN IMPROVED FORM OF TEMPERATURE REGULATOR}

$\mathrm{N}_{\mathrm{N}} \mathbf{8 8 2}$, at the request of the Board of Trade, the Royal Society appointed a Committee, consisting of Sir G. Airy, Col. Clark, and Prof. Stokes, to advise on the question of improving the existing means of the comparison of standards of length at the Standard Office. In their report the Committee suggested improvements in the arrangement for securing greater uniformity and steadiness of temperature in the bars under comparison. As a first step in this direction, the Cambridge Scientific Instrument Company were requested to investigate the subject of temperature regulators, and to consider the general design of a comparing apparatus. They proposed that the standards, some hours before they were observed, should be placed in metal cases and immersed in a bath containing water; and that they should not be disturbed during the process of observation. If the uniformity of temperature of the water could be ensured, it would secure the equality of temperature of the standards and remove one of the greatest difficulties in the construction of a satisfactory comparing apparatus.

After some preliminary trials a regulator was constructed similar to that used at the Bureau International des Poids et Mesures at Sères. ${ }^{1}$ Its action depends on the variation of pressure of a saturated vapour, caused by a change of temperature. The pressure on the volatile liquid and vapour is due to the atmosphere, as well as to a column of mercury ; consequently the regulated temperature will vary with any change in the atmospheric pressure. In the following experiments the corresponding change of temperature for one inch alteration of the barometer was about $0^{\circ} 37 \mathrm{C}$. The accuracy of the regulator therefore depends on the constancy of the atmospheric pressure,

I See "Travaux et Mémoires du Bureau International des Poids et and to overcome this serious disadvantage an arrangement was devised for maintaining a constant pressure on the volatile liquid.

An iron bath, D (Fig. I), containing water, was placed in a wooden box. The intermediate space was filled with sawdust ; this was done to minimise the unequal cooling due to the varying temperature of the room. The two ends of a $U$-shaped tube were fixed into the bottom of the iron bath and passed through holes in the side of the wooden box. The water was kept warm by means of two gas-flames placed under a part of this tube. One of the gas-flames was connected to the regulator and the other direct to the gas-main. The object of the second flame was to re-light the regulated gas-jet in case it should have been extinguished by the regulator.

The water in the bath was kept thoroughly stirred by air forced through it by means of bellows. These were placed inside the box in order to keep them warm, and also for the more important reason of avoiding the currents of air which would otherwise be produced at each stroke. The air used for

\section{Fia 1}

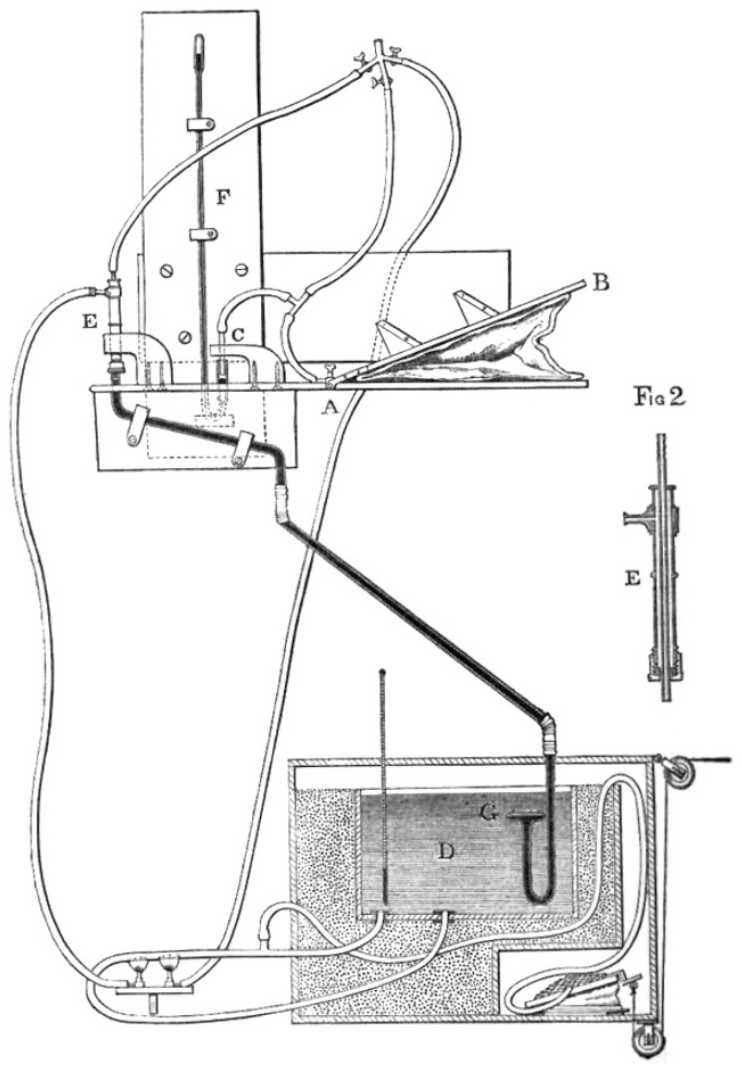

stirring was thus saturated with aqueous vapour, and did not cool the water in the bath by absorbing moisture from it. The nozzle of the bellows was connected to the $U$-shaped tube by a branch inserted just above the point where the gas-flame was applied. The air thus pumped through the upper part of the $U$-tube caused a rapid circulation of water through it. This method has the advantage of applying the heat in a manner which does not tend to make the water in one part of the bath perceptibly hotter than the rest.

The volatile liquid in the regulator was a mixture of methyl-chloride and ethyl-chloride, boiling at about $23^{\circ} \mathrm{C}$ under the normal atmospheric pressure. It was contained in a flat bulb, G, blown at the end of a glass tube, and was under a head of mercury. The glass tubes containing the mercury were connected by short lengths of canvaslined india-rubber tube. A double brass tube was secured to the open end of the regulator, $\mathrm{E}$; this is shown enlarged in 
Fig. 2. The gas entered by the inner tube, which passed down to the surface of the mercury, and the outer tube was connected with the gas-burner placed under the $U$-shaped heating-tube. Thus a rise of mercury in the regulator reduced the supply of gas to the burner. The cross-section of the flat glass bulb at the common surface of the mercury and volatile liquid was large compared with the cross-section at the upper end of the regulator; thus nearly all the increase in height due to expansion of the volatile liquid and vapour takes place at the upper end of the regulator, and the level of the common surface of the mercury and volatile liquid remains nearly constant.

The most interesting part of the apparatus is the arrangement for compensating for the variation of atmospheric pressure. With this object a barometer in the form of a bent tube is fixed at $F$. To simplify the explanation we will suppose that the atmospheric pressure diminishes by an amount equal to a head of one inch of mercury ; this will cause the mercury in the open end of the barometer to rise half an inch. If the regulated gasflame is to be extinguished when there is a constant pressure on the volatile liquid, then the tube $\mathrm{E}$ must be raised one inch; thus it must move in the same direction as and twice the amount of the exposed surface of the mercury in the barometer. To accomplish this the upper part of the regulator was attached to a board turning about a horizontal axis, A. A gas-bag was placed between the projecting end of this board and a fixed board, B. The board turning about $\mathrm{A}$ was so weighted as to tend to close the bag. The nozzle of the bag was connected to the gas-main, and a branch pipe led to a small tube, c, passing down the open end of the barometer. This small tube was fixed by a bracket to the movable board half-way between the upper end of the regulator and the pivot A. Now if the mercury rises in the open end of the barometer it closes the tube $\mathrm{c}$, and the gas from the main passes into the bag, forces the boards apart, and raises both the upper end of the regulator and the tube $\mathrm{C}$, until the escape restores the equilibrium. The flexible indiarubber connections in the glass tubes allow the necessary movement to take place. This arrangement is of interest, as the pressure of the gas-supply is the motive-power for automatically moving a piece of mechanism in a required manner.

The apparatus was kept in action for fourteen days without readjustment, but the stirring of the water was discontinued at night. The thermometer was read about ten times a day, and from July $\mathrm{I} 8$ to August $\mathrm{I}$ the extreme readings were $30^{\circ} .90 \mathrm{C}$. and $30^{\circ} .86 \mathrm{C}$. The greatest change of temperature during any day was $0^{\circ} \cdot 04 \mathrm{C}$., the least observed change during any day was $0^{\circ}$ or C., and the longest period during which no change was observable was from I 2.30 p.m. on July 20 , to I p.m. the following day. At night, when the stirring was discontinued, the variation of the temperature was greater, but it settled down to its normal amount shortly after the stirring began. In a properly-constructed comparing-room the change of temperature would have been less. On one occasion the barometer rose rapidly, nearly half an inch in twenty-four hours, and during this time the temperature of the water did not vary perceptibly. If the barometer had not been attached to the regulator, this change of pressure on the volatile liquid would have produced a change of $\mathrm{O}^{\circ} \cdot \mathrm{I}_{4} \mathrm{C}$. in the bath.

The apparatus was roughly made in an experimental form, but the results were highly satisfactory. There were no doubt errors in the readings of the thermometer. Sir William Thomson, in his article on "Heat" in the "Encyclopæedia Britannica," describes an error which may be introduced owing to the mercury in the stem of a thermometer remaining at rest whilst slight changes of temperature are occurring, and then moving suddenly into a new position, where it again remains at rest. This phenomenon was observed in the very delicate thermometer used.

The variation of temperature due to the expansion of the mercury in the barometer and regulator was perceptible, and agreed roughly with the amount arrived at by calculation. Very small errors were also probably introduced by the following causes : the sticking of the mercury in the regulator and the barometer; variation of the gas-pressure; imperfections in the mechanism and of the vacuum in the barometer. There can, however, be little doubt that the errors produced by these and other causes could be reduced to an inappreciable amount, and if the apparatus were placed in a room of fairly constant temperature, remarkable results could be obtained.

IIORACE DARIVIN

\section{SCIENTIFIC SERIALS}

Fournal of the Russian Chemical and Physical Society, vol. xviii., fasc. ii. - On the analysis of platinum ores, by F. Willm. All former methods of the separation of noble metals, though sufficient for technical purposes, are considered not exact for the scientific determination. Electrolytic method is recommended. On the thermic effects of the replacement of hydrogen by bromine in the aromatic compounds, by $E$. Werner.-On cholanic and bileanic acids, by P. Latchinoff. Both having been obtained from cow's bile and formula proposed for the former $\mathrm{C}_{25} \mathrm{H}_{38} \mathrm{O}_{7}+\frac{1}{4} \mathrm{H}_{2} \mathrm{O}$, and for the Jatter $\mathrm{C}_{25} \mathrm{H}_{36} \mathrm{O}_{8}+\frac{1}{4} \mathrm{H}_{2} \mathrm{O}$. Contribution to the theory of the influence of the decomposition of a body due to heat or to mechanical influences, on its magnetism, by P. Bakmetieff.--Thermo-electrical researches, by the same author. The starting-point for these researches being the fact observed by the author, that the thermo-electro generative force in the metal rods, which serve as thermo-elements, undergoes variations under the influence of the contraction or expansion of the rods parallel to those of magnetism in the same metals and from the same causes.

Rendiconti del Reale Istituto Lombardo, February 18.-State of public instruction in Italy, by Prof. A. Amati. In general the results here tabulated of an inquiry into the present state of instruction throughout the peninsula show that the number of unlettered is in direct proportion with that of the criminal classes. - On a phenomenon of intermission in the sense of hearing, by Prof. A. Raggi. It is shown that under certain conditions regularly recurring sounds strike the auditory faculty in rhythmically recurring waves of greater and less intensity. The phenomenon is regarded as the direct result of perception, the reflex act represented by the awakened attention not being produced with a uniform degree of energy continued throughout the duration of the stimulus, the lack of uniformity being itself due to the feeble degree of excitement.-Note on a simple and obvious, but not hitherto noticed deduction from Taylor's formula in infinitesimal analysis, by Gian Antonio Maggi.Remarks on a normal metamorphosis of the scented violet due to the presence of the larva of Cecidomyia ciestructor, by Dr. S. Calloni.

\section{SOCIETIES AND ACADEMIES \\ LONDON}

Royal Society, March 25.- " On the Changes produced by Magnetisation in the Length of Iron Wires under Tension." By Shelford Bidwell, M.A., LL.B. Communicated by Prof. F. Guthrie, F.R.S.

In a paper communicated to the Royal Society about a year ago, the author discussed the results of certain experiments made by Joule in relation to the effects of magnetism upon the dimensions of iron and steel bars.

It is well known that the length of an irun rod is in general slightly increased by magnetisation. Joule enunciated the law that the elongation is proportional in a given bar to the square of the magnetic intensity, and that it ceases to increase after the iron is fully saturated. The author's experiments, made with a greater range of magnetisin $r$ forces and with thinner rods than those used by Joule, showed that if the magnetising current were gradually increased after the so-called saturation point of the iron bad been reached, the elongation, instead of remaining at a maximum, was diminished, until, when the current had attained a certain strength, the original length of the rod was unaltered, and if this strength were exceeded, actual retraction was produced.

Joule also found that when the experiment was performed upon an iron wire stretched by a weight, the magnetic extension was in all cases diminished, and if the weight were considerable, magnetisation caused retraction instead of elongation. From these facts he appears to have formed the conclusion that, under a certain critical tension (differing for different specimens of iron, but independent of the magnetising force), magnetisation would produce no effect whatever upon the dimensions of the wire. In one of his experiments a certain iron wire loaded with a weight of $408 \mathrm{lbs}$. was found to be slightly elongated when magnetised; the weight was then increased to 740 lbs., with the result that magnetisation was accompanied by a slight retraction. In both cases the magnetising currents varied over a considerable range, and the smaller ones were without any visible effect. Commenting upon these results, Joule conjectured that "with a tension of about 600 lbs. (which number is roughly 